\title{
Frequencies of milk protein variants and haplotypes estimated from genotypes of more than 1 million bulls and cows of 12 French cattle breeds
}

\author{
M. P. Sanchez, ${ }^{1 *}$ (1) S. Fritz, ${ }^{1,2}$ C. Patry, ${ }^{3}$ A. Delacroix-Buchet, ${ }^{1}$ (ㄷ and D. Boichard ${ }^{1}$ (1) \\ ${ }^{1}$ Université Paris Saclay, INRAE, AgroParisTech, GABI, 78350 Jouy-en-Josas, France \\ ${ }^{2}$ Allice, 75012 Paris, France \\ ${ }^{3}$ Valogene, 75012 Paris, France
}

\begin{abstract}
Due to their major effects on milk composition and cheese-making properties and their putative effects on human health, there is a great deal of interest in bovine milk protein variants. The objectives of this study were to estimate frequencies of milk protein variants and haplotypes in 12 cattle breeds as well as their trends over time to assess the effect of selection on milk traits. Milk protein variants and haplotypes were identified from SNP genotype data from more than 1 million animals from 12 dairy, beef, or dual-purpose cattle breeds that had been genotyped for genomic selection. We examined a total of 15 loci in the genes that encode $\beta$-lactoglobulin $(\beta-\mathrm{LG})$ and 3 caseins $\left(\alpha_{\mathrm{S} 1}-\mathrm{CN}, \beta-\mathrm{CN}\right.$, and $\kappa-\mathrm{CN}$ ); genotypes were directly called from customized SNP chips $(50.6 \%)$ or imputed $(49.4 \%)$. Variants $A$ and $B$ of $\beta$-LG were frequent in the 12 breeds. For the caseins, we found 3 variants for $\alpha_{\mathrm{S}_{1}} \mathrm{CN}(B, C$, and $D), 6$ for $\beta$-CN $(A 1, A 2, A 3, B, C$, and $I)$, and 5 for $\kappa_{-} \mathrm{CN}(A, B, C, D$, and $E)$. For $\alpha_{\mathrm{S}_{1}} \mathrm{CN}$, the $B$ variant was the most frequent in all breeds except Jersey. For $\beta$-CN, the $A 2$ variant was the most abundant in all breeds except Tarentaise, although in Normande animals, the $I$ variant $(30.9 \%)$ was almost as common as $A 2(39.7 \%)$. The $C$ variant was very rare except in the Tarentaise sample $(4.8 \%)$. The most frequent variant for $\kappa_{-} \mathrm{CN}$ was $A$ in 5 breeds (including Holstein), and $B$ in the 7 other breeds. The $B$ variant was present at a particularly high frequency in Jersey $(82.6 \%)$ and Normande $(85.5 \%)$ animals. The $C$ and $E$ variants of $\kappa$-CN appeared to be particularly frequent in the Tarentaise $(12.7 \%)$ and Holstein $(9 \%)$ breeds, respectively. We found 20 haplotype combinations of $\alpha_{S 1}-\beta-\kappa$ $\mathrm{CN}$ that were present at a frequency $>0.1 \%$ in at least
\end{abstract}

Received March 9, 2020

Accepted May 27, 2020.

*Corresponding author: marie-pierre.sanchez@inrae.fr one breed; however, only 6 to 9 haplotypes were found in any given breed, demonstrating a strong degree of linkage disequilibrium. The most frequent haplotypes were $B-A 1-A, B-A 2-A, B-A 2-B, B-I-B, C-A 2-A$, and $C-A 2-B$. Some alleles were predominantly found in only one haplotype, such as the $E$ and $C$ variants of $\kappa$-CN and the $I$ variant of $\beta-\mathrm{CN}$, which were mainly found in the $B-A 1-E, B-A 1-C$, and $B-I-B$ haplotypes, respectively. We observed changes in the frequency of certain variants over time in several breeds, such as an increase in the frequency of variants $A$ of $\beta-\mathrm{LG}, I$ of $\beta-\mathrm{CN}$, and $B$ of $\kappa-\mathrm{CN}$. With these results, we update and complete frequency data that were first estimated 30 to $50 \mathrm{yr}$ ago, and, for the first time in these breeds, we assess the effect of selection on milk protein variants.

Key words: milk protein, variant and haplotype frequencies, genotype, French cattle breeds

\section{INTRODUCTION}

Cow milk contains 6 major proteins: $\alpha_{\mathrm{S}^{-}} \mathrm{CN}, \alpha_{\mathrm{S}^{-}}$ $\mathrm{CN}, \beta-\mathrm{CN}$, and $\kappa-\mathrm{CN}$ (representing about $80 \%$ of the total protein content) and the whey proteins $\alpha$-LA and $\beta$-LG. Long before the availability of DNA molecular markers, some of the genetic polymorphisms of milk proteins could be directly identified by their protein phenotypes using electrophoresis (Aschaffenburg and Drewry, 1957). With that technique, it is possible to distinguish forms or variants of the same protein that differ in charge or size. In bovines, the main variants in milk proteins are typically caused by variations in the sequence of amino acids and, more precisely, from missense variations in the exons of genes (Farrell et al., 2004). The main variations in milk protein genes that induce cow protein variants are known (Martin et al., 2002). The $\alpha_{S^{-}}(C S N 1 S 1), \beta-(C S N 2), \alpha_{S 2^{-}}(C S N 1 S 2)$, and $\mathrm{\kappa}^{-}(C S N 3) \mathrm{CN}$ genes are closely linked in a $248-\mathrm{kb}$ region on chromosome 6 (between 85.4 and $85.7 \mathrm{Mb}$ on the ARS-UCD1.2 genome assembly), which comprises the casein locus or haplotype. The genes that encode 
the $\alpha$-LA and $\beta$-LG whey proteins are located on chromosomes 5 (LALBA, 31.2 Mb) and 11 (PAEP, 103.2 $\mathrm{Mb})$, respectively. To date, few variants have been identified in the LALBA and CSN1S2 genes in cattle breeds, particularly in French breeds, whereas many polymorphisms have been described in the other 4 genes: CSN1S1, CSN2, CSN3, and PAEP (Grosclaude, 1988; Caroli et al., 2009).

There is a great deal of scientific interest in milk protein variants because they have major effects on milk composition and cheese-making properties (Ng-KwaiHang et al., 1984; Bovenhuis et al., 1992) and they may have effects on human health (He et al., 2017). We can assume that intensive selection to increase yields of milk, protein, and fat in dairy cattle has resulted in changes in the frequency of these variants. It is therefore important to review the current situation in cattle breeds. With modern methods of molecular analysis, it is now much easier to determine genetic variants in DNA than in protein. Sequencing is the method of choice because it can detect all variants, although sample sizes are still limited (Meier et al., 2019). Genotyping is cheap and can be multiplexed with many genetic markers on SNP chips. Since the development of the low-density SNP BeadChip from Illumina Inc. (San Diego, CA; Boichard et al., 2012), bovine SNP chips can be customized to include additional variants. Because of their effects on milk production traits, known SNPs in CSNS1, CSN2, CSN3, and PAEP were added in 2013 to the Eurogenomics BeadChip, which is routinely used for genomic selection in Europe (Boichard et al., 2018). Fifteen of these SNPs (3 to 7 per gene) are missense variants that affect the structure of the resulting protein, and their inclusion on the bead chip has enabled the genotyping of both male and female cattle for the main protein variants of these genes. In recent years, a dramatic expansion of genomic selection programs has created new possibilities for the characterization of these protein variants in all French cattle breeds for which a selection program has been developed. In November 2019, the SIGENO database hosted by INRAE (Institut national de recherche pour l'agriculture, l'alimentation et l'environnement, Paris, France) on behalf of French breeders included more than 1 million genotypes from 12 dairy, beef, or dual-purpose cattle breeds.

Milk protein variants are of special interest because they affect fat and protein milk composition, as well as technological properties of milk. Some of them are also thought to affect human health. In addition, casein genes are grouped in haplotypes that are transmitted almost without recombination. Therefore, frequencies of casein variants do not vary independently of each other, potentially leading to unexpected or undesirable changes. To update and build upon the results of
Grosclaude (1988), published more than 30 yr ago, the goal of this study was to present recent estimates of the frequencies of protein variants and casein haplotypes in 12 French cattle breeds, and to describe how those frequencies have evolved over time for assessing the effect of selection on milk production and composition traits, based on a large number of animals genotyped mainly for the purpose of genomic selection.

\section{MATERIALS AND METHODS}

\section{Animals, Genotyping, and Imputation}

More than 1 million animals representing 12 French dairy (Abondance, ABO; Jersey, JER; Brown Swiss, BSW; Holstein, HOL; Montbéliarde, MON; Tarentaise, TAR), dual-purpose (Normande, NOR; Simmental, SIM; Vosgienne, VOS), or beef (Blonde d'Aquitaine, BLA; Charolaise, CHA; Limousine, LIM) cattle breeds of Alpine (CHA, ABO, BSW, MON, TAR, SIM, and VOS), Northwest (Oceanic; HOL, JER, and NOR), or Southern (Iberic; BLA and LIM) origins (Grosclaude et al., 1990; Jann et al., 2002; Gautier et al., 2010) were genotyped, mainly for the purpose of genomic selection (Table 1). All genotypes obtained from international exchanges were excluded. The number of genotyped animals differed greatly depending on the breed. With 543,897, 289,875, and 96,558 genotyped animals, respectively, the 3 main French dairy breeds (HOL, MON, and NOR) alone accounted for nearly $88 \%$ of the total number of animals with genotypes. These were followed by the beef breeds CHA, BLA, and $\operatorname{LIM}(37,633,14,878$, and 14,439, respectively). In the other breeds, which are of regional importance in France, fewer animals had genotypes available: 9,979 for ABO, 8,628 for BSW, 5,573 for TAR, 3,731 for VOS, 3,312 for SIM, and 1,401 for JER.

In all breeds, most animals were candidates for genomic selection and were born in the last $10 \mathrm{yr}$. In dairy breeds, 80 to $94 \%$ of these young animals were females, whereas in beef breeds, less than 50\% were females. Older animals (about 20,000) were progeny-tested bulls and constituted the initial reference populations for genomic evaluation. This sample is a nearly complete representation of the French AI bull population born from 1990 to 2008. Before 1990, the sample was more limited and included mainly elite bulls. The year of birth of the oldest genotyped bulls of each breed ranged from the early 1950s (HOL and CHA) to 2004 (JER) but, in most of the breeds, the oldest genotyped bulls were born in the 1960s and 1970s.

All animals were genotyped between 2008 and 2019, and thus different versions of Illumina chips were used (Table 2), with or without customization. High-, me- 
Table 1. Description of the 12 cattle breeds, with information on the genotyped bulls and cows

\begin{tabular}{|c|c|c|c|c|c|c|c|c|}
\hline $\begin{array}{l}\text { Breed } \\
\text { abbreviation }\end{array}$ & Breed name & Bulls (no.) & Cows (no.) & $\begin{array}{c}\text { Total } \\
\text { animals (no.) }\end{array}$ & $\begin{array}{l}\text { Birth year of } \\
\text { oldest bulls }\end{array}$ & $\begin{array}{l}\text { Birth year of } \\
\text { oldest cows }\end{array}$ & Production & Origin \\
\hline BLA & Blonde d'Aquitaine & 8,648 & 6,230 & 14,878 & 1962 & 1987 & Beef & Iberic \\
\hline $\mathrm{ABO}$ & Abondance & 1,097 & 8,882 & 9,979 & 1970 & 1981 & Dairy & Alpine \\
\hline BSW & Brown Swiss & 1,545 & 7,220 & 8,765 & 1981 & 1979 & Dairy & Alpine \\
\hline $\mathrm{HOL}$ & Holstein & 110,330 & 433,567 & 543,897 & 1950 & 1950 & Dairy & Oceanic \\
\hline TAR & Tarentaise & 907 & 4,666 & 5,573 & 1964 & 1999 & Dairy & Alpine \\
\hline NOR & Normande & 15,549 & 81,009 & 96,558 & 1970 & 1980 & Dual-purpose & Oceanic \\
\hline SIM & Simmental & 1,483 & 1,829 & 3,312 & 1973 & 2003 & Dual-purpose & Alpine \\
\hline VOS & Vosgienne & 238 & 3,493 & 3,731 & 1968 & 1997 & Dual-purpose & Alpine \\
\hline
\end{tabular}

dium-, or low-density chips, which contained, respectively, around $777 \mathrm{k}$ (HD), 50k (MD), and 7 to $20 \mathrm{k}$ (LD) SNPs, were used in each breed (Table 2). Only a small proportion of the animals in each breed were genotyped with the HD chip, from $0.1 \%$ in HOL to $7.1 \%$ in SIM, and none in JER. Most of the 4,361 HD genotypes (from 182 to 817 per breed, average of 396) originated from research projects. The percentage of animals genotyped with an MD chip varied depending on the breed, from $18 \%$ in MON to $92.6 \%$ in SIM. Likewise, the percentage of animals in each breed that were genotyped with an LD chip was variable, from $0.2 \%$ (SIM) to $81.8 \%$ (MON). To obtain high imputation accuracy, it was recommended in each breed to accumulate MD genotypes before switching to LD, and this explains the higher proportion of MD genotypes when the total number of genotypes was limited. Since 2013, in addition to the standard content of generic SNPs, it has been possible to use specific versions of MD and LD chips that include additional SNPs, such as the missense variants in the milk protein genes. For
11 of the 12 breeds, a relatively large proportion of the animals had been genotyped with these customized chips (63.6 to $91.8 \%$ ), whereas they were used for only $30.1 \%$ of the LIM animals (Table 2). Repeatability of genotyping results across chip versions is a crucial aspect. For that purpose, we set up a high-level quality control procedure. For each new chip and before its use in large-scale routine production, the same batch of 288 animals selected to cover a large genetic variability was re-genotyped and concordance between their genotypes was checked across chips. When some genotypes differed, SNP chip clusters were inspected and, when necessary, adjusted. Finally, markers that remained not interpretable were removed, but this never occurred for milk protein variants. In addition, these variants were always present (at least) twice on the same chip and all tests were required to be concordant. Because of this validation effort, we considered that genotyping results did not depend on the chip version.

The raw genotypes were then processed with the quality control procedure used in the French national

Table 2. Percentage of animals among the 12 French cattle breeds ${ }^{1}$ that were genotyped using generic or customized (with missense SNPs in protein-coding genes) chips of various densities

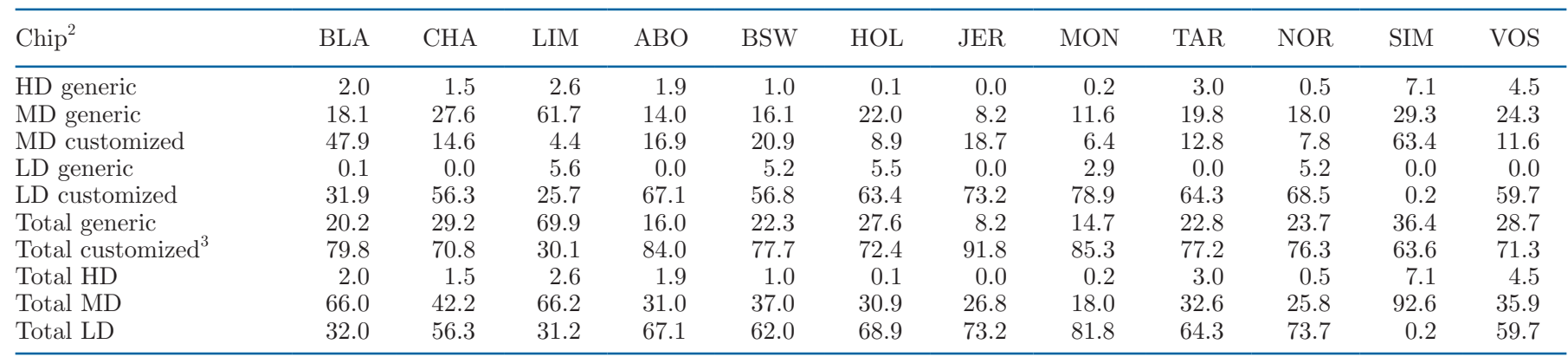

${ }^{1}$ Blonde d'Aquitaine (BLA), Charolaise (CHA), Limousine (LIM), Abondance (ABO), Brown Swiss (BSW), Holstein (HOL), Jersey (JER), Montbéliarde (MON), Tarentaise (TAR), Normande (NOR), Simmental (SIM), and Vosgienne (VOS).

${ }^{2}$ High density (HD; $\approx 777 \mathrm{k}$ SNP), medium density (MD; $\approx 50 \mathrm{k}$ SNP), or low density (LD; $\approx 10-20 \mathrm{k}$ SNP).

${ }^{3}$ Milk protein variants were present on all customized chips and imputed for the generic chip. 
evaluation system (Boichard et al., 2012): (1) only animals with an individual call rate higher than $95 \%$ were kept, (2) SNPs with a call rate lower than $90 \%$ were deleted, (3) for generic markers (but not for custom markers), a minor allele frequency $>1 \%$ in at least one major French dairy cattle breed (HOL, MON, or NOR) was required, and (4) SNPs with genotype frequencies in Hardy-Weinberg equilibrium $\left(P>10^{-4}\right)$ were kept. Following this procedure, 53,469 SNPs were retained, which included 15 missense variants in milk protein genes.

To recover as complete information as possible, genotypes of all animals were imputed within breed to these $53,469 \mathrm{SNP}$, all present on the most recent version of the customized MD chip by Eurogenomics (EuroGMD BeadChip, Illumina Inc.). Imputation was performed with FImpute software (Sargolzaei et al., 2014). Because imputation involves phasing (i.e., determination of the parental origin of alleles), casein haplotypes were obtained automatically and simultaneously. Imputation accuracy was high in all breeds $[<0.5 \%$ genotype error rate in the large dairy breeds, 1.1 to $1.5 \%$ in the beef breeds (Saintilan et al., 2014), and $<1 \%$ in the regional dairy breeds (Sanchez et al., 2016)]. All real or imputed milk protein genotypes were then included in further analysis and frequencies were obtained by allele counting.

\section{Correspondence Between Protein Variants and SNP Genotypes}

After imputation, 15 missense variants located in the exons of the casein and $P A E P$ genes were characterized for all genotyped animals. For each gene, between 2 and 6 SNPs from the chip were used to call 3 to 7 different variants of the resulting protein (CSN1S1: 2 SNPs, 3 variants; CSN2: 6 SNPs, 7 variants; CSN3: 3 SNPs, 5 variants; PAEP: 4 SNPs, 5 variants). The correspondence between DNA variants and protein variants is given in Figure 1. For CSN3, a combination of 2 mutations is required to distinguish alleles $C$ and $D$. In $P A E P$, alleles $A$ and $B$ differ in 2 variants in complete linkage disequilibrium. Among these 15 SNPs in the 4 milk protein genes, it was therefore possible to distinguish variants $B, C$, and $D$ of $\alpha_{\mathrm{S1}^{-}} \mathrm{CN} ; A 1, A 2$, $A 3, B, C, F$, and $I$ of $\beta-\mathrm{CN} ; A, B, C, D$, and $E$ of $\kappa-\mathrm{CN}$; and $A, B, C, D$, and $W$ of $\beta$-LG. In addition to allelic frequencies for the 4 proteins, we also calculated the frequencies of casein haplotypes (CSNS1-CSN2-CSN3) among the 12 breeds. In each breed, we first calculated whole-population frequencies and then estimated the trend of frequencies over time. The frequencies were computed based on animal birth year for males and females separately, and results were only retained if the year in question contained at least 50 genotyped bulls or cows.

To highlight patterns of similarity in the milk proteins between breeds, we applied a hierarchical clustering analysis, based on casein haplotypes, using the "hclust" function of the R package (Müllner, 2013) "fastcluster."

\section{RESULTS}

\section{Frequencies of Milk Protein Variants}

Frequencies of protein variants are presented for each breed in Table 3. Among the 12 breeds, variants $A$ and $B$ were the main variants of $\beta-\mathrm{LG}$. The $A$ variant was the most frequent in BLA (71.6\%), LIM (61.8\%), CHA (60.5\%), SIM (59.2\%), HOL (58.5\%), JER (55\%), and MON (54.3\%), whereas $B$ was most frequent in BSW $(68.8 \%)$, VOS (68.8\%), TAR (68.2\%), NOR (57\%), and $\mathrm{ABO}(53.5 \%)$. A rare variant $(D)$ was found in SIM $(2.3 \%)$ and $\mathrm{ABO}(0.3 \%)$, and at a very low frequency $(<0.1 \%)$ in the HOL, MON, NOR, and BLA samples. We did not identify the $C$ and $W$ variants in these 12 breeds.

For caseins, 3 variants were found for $\alpha_{\mathrm{S} 1}-\mathrm{CN}(B, C$, and $D), 6$ for $\beta-C N(A 1, A 2, A 3, B, C$, and $I)$ and 5 for ${ }_{\kappa}-\mathrm{CN}(A, B, C, D$, and $E)$. Therefore, with the exception of the $\kappa-C N F$ variant, we detected all possible casein variants that can currently be distinguished using SNP analysis. The most frequent casein variant in each breed was $B$ or $C$ for $\alpha_{\mathrm{S}_{1}} \mathrm{CN}, A 1$ or $A 2$ for $\beta-\mathrm{CN}$, and $A$ or $B$ for $\kappa$-CN.

For $\alpha_{\mathrm{S}_{1}} \mathrm{CN}$, the $B$ variant was found to be the most frequent in 11 of the 12 breeds and was highly predominant in 8 breeds (HOL, 99.6\%; MON, 97.5\%; VOS, 94.1\%; SIM, 94.1\%; BLA, 93.7\%; BSW, 88.9\%; LIM, 86.8\%; and CHA, 86.2\%). Jersey was the only breed in which the $C$ variant was most frequent $(59.1 \%$, compared with $40.9 \%$ for the $B$ variant). The $D$ variant was found in the BLA, CHA, LIM, and HOL samples, but at a frequency $<0.1 \%$ in each case.

We identified a larger number of polymorphisms for $\beta$-CN, but the $A 2$ variant was the most abundant in all breeds (from $39.7 \%$ in NOR to $82.8 \%$ in ABO) except TAR, in which the $A 1$ variant was slightly more frequent ( $49.7 \%$ vs. $45.8 \%$ for the $A 2$ variant). In NOR, the $I$ variant $(30.9 \%)$ was almost as common as the $A 2$ variant (39.7\%); it was also found at a relatively high frequency in MON (16.7\%), VOS (12.4\%), BLA $(10.5 \%)$, and HOL $(8.4 \%)$. One of the characteristics of the MON breed was a high frequency of the $B$ variant $(29.1 \%)$, which also appeared at a relatively high frequency in NOR (18.6\%), BSW (14.6\%), and CHA 


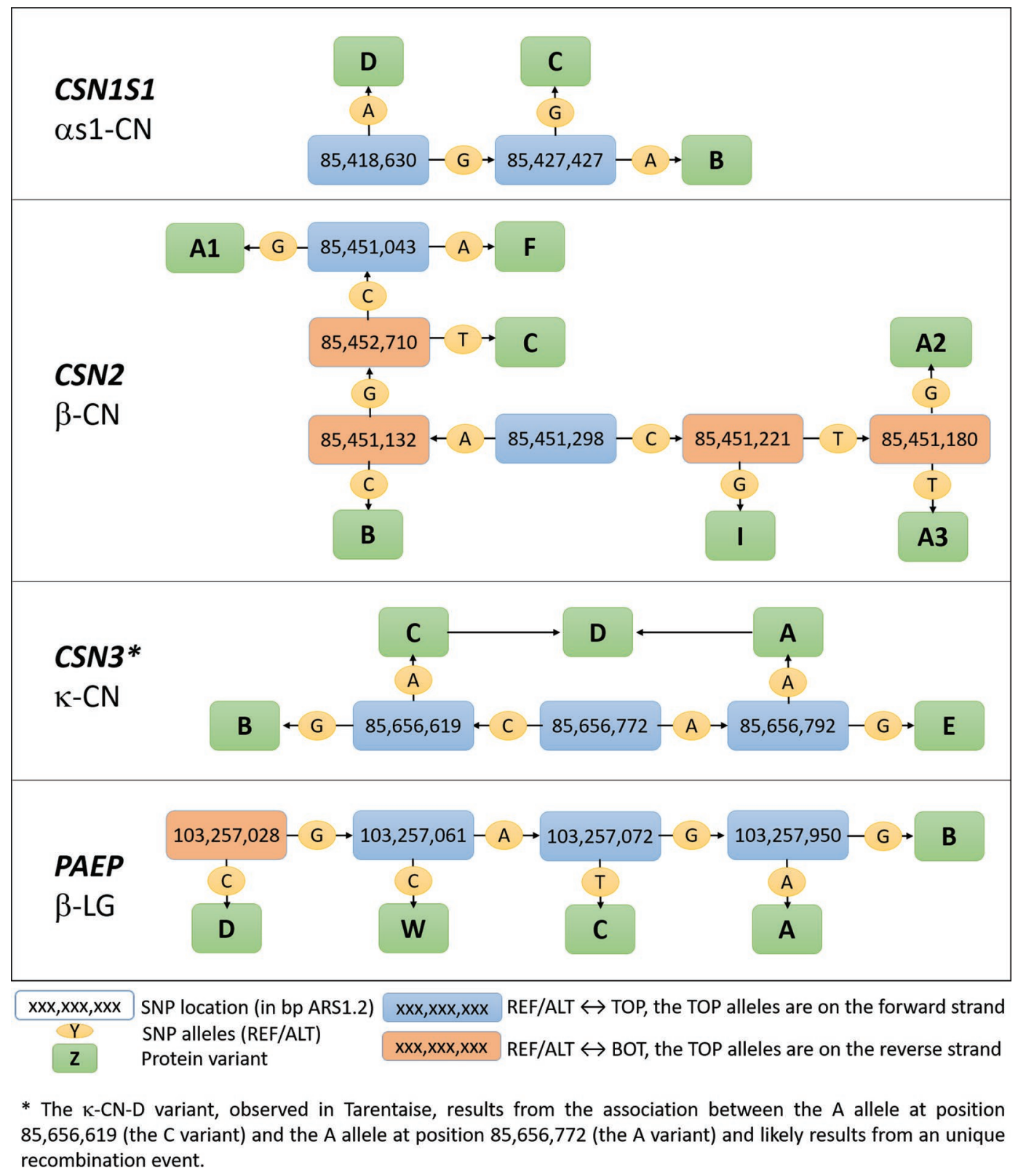

Figure 1. Relationships between missense SNPs and protein variants for the genes that encode the bovine milk proteins $\alpha_{S_{1}-C N}$ (CSN1S1), $\beta$-CN (CSN2), $\kappa-C N ~(C S N 3)$, and $\beta$-LG (PAEP). REF and ALT indicate reference and alternate alleles on the ARS-UCD1.2 assembly.

(13.4\%). The $C$ variant was rarely found, except in TAR $(4.8 \%)$ and to lesser extent in CHA (1.1\%).

The most frequent variant for $\kappa-\mathrm{CN}$ was $A$ in BLA, HOL, ABO, SIM, and VOS, and $B$ in the 7 other breeds. The $B$ variant was found at a particularly high frequency in JER (82.6\%) and NOR (85.5\%), while the frequencies of $A$ and $B$ variants were more balanced in all other breeds. Three other variants appeared to be breed-specific: the $C$ and $D$ variants were found exclusively in TAR (12.7\% and $0.12 \%$, respectively) whereas the $E$ variant was present in HOL samples $(9.5 \%)$ and at frequencies $<1 \%$ in JER and MON.

\section{Casein Haplotype Frequencies}

In the entire sample, 20 of the possible $90(3 \times 6 \times$ 5) $\alpha_{S 1}-\beta-\kappa$-casein haplotype combinations were found at a frequency $>0.1 \%$ in at least one breed (Table 4 ). One haplotype was always predominant in each breed, with a frequency above $0.6,0.4$, and 0.3 in 2,5 and 11 
Table 3. Percentages of $\beta-\mathrm{LG}, \alpha_{\mathrm{S1}^{-}} \mathrm{CN}, \beta-\mathrm{CN}$, and $\kappa-\mathrm{CN}$ variants in 12 French cattle breeds ${ }^{1}$

\begin{tabular}{|c|c|c|c|c|c|c|c|c|c|c|c|c|c|}
\hline Protein & Variant $^{2}$ & BLA & CHA & LIM & $\mathrm{ABO}$ & BSW & HOL & JER & MON & TAR & NOR & SIM & VOS \\
\hline \multirow{2}{*}{$\beta-\mathrm{LG}$} & $B$ & 28.4 & 39.5 & 38.2 & 53.5 & 68.8 & 41.5 & 45.0 & 45.7 & 68.2 & 57.0 & 38.4 & 68.8 \\
\hline & $D$ & $<0.1$ & 0 & 0 & 0.31 & 0 & $<0.1$ & 0 & $<0.1$ & 0 & $<0.1$ & 2.3 & 0 \\
\hline \multirow[t]{3}{*}{$\alpha_{\mathrm{S} 1}-\mathrm{CN}$} & $B$ & 93.7 & 86.2 & 86.8 & 55.9 & 88.9 & 99.7 & 40.9 & 97.5 & 66.7 & 73.4 & 94.1 & 94.1 \\
\hline & $C$ & 6.2 & 13.8 & 12.5 & 44.1 & 11.1 & 0.34 & 59.1 & 2.5 & 33.3 & 26.6 & 5.9 & 5.9 \\
\hline & $D$ & $<0.1$ & $<0.1$ & 0.69 & 0 & 0 & $<0.1$ & 0 & 0 & 0 & 0 & 0 & 0 \\
\hline \multirow{4}{*}{$\beta-\mathrm{CN}$} & $A 3$ & 0 & $<0.1$ & $<0.1$ & $<0.1$ & $<0.1$ & 0.26 & 0 & $<0.1$ & 0 & 1.64 & $<0.1$ & 0 \\
\hline & $B$ & 7.04 & 13.43 & 8.17 & $<0.1$ & 14.62 & 2.09 & 12.99 & 29.10 & 0 & 18.59 & 3.80 & 0.20 \\
\hline & $C$ & 0.21 & 1.10 & 0.39 & 0.31 & $<0.1$ & $<0.1$ & 0 & $<0.1$ & 4.75 & $<0.1$ & 0 & 0.48 \\
\hline & $I$ & 10.5 & 2.4 & 2.8 & 1.1 & 0.16 & 8.4 & 6.0 & 16.7 & 0 & 30.9 & 4.7 & 12.4 \\
\hline$\kappa-\mathrm{CN}$ & $A$ & 53.8 & 34.4 & 46.9 & 64.8 & 25.6 & 56.9 & 16.9 & 38.2 & 30.5 & 14.5 & 71.8 & 65.5 \\
\hline
\end{tabular}

${ }^{1}$ Blonde d'Aquitaine (BLA), Charolaise (CHA), Limousine (LIM), Abondance (ABO), Brown Swiss (BSW), Holstein (HOL), Jersey (JER), Montbéliarde (MON), Tarentaise (TAR), Normande (NOR), Simmental (SIM), and Vosgienne (VOS).

${ }^{2}$ Only variants found with a frequency $>0.1 \%$ in at least one breed were included.

breeds, respectively. Among breeds, the most frequent casein haplotype varied: $B-A 1-A(32.2 \%$ in SIM and $32.4 \%$ in VOS), $B-A 2-A(43.4 \%$ in BLA, $40.1 \%$ in LIM, and $43.7 \%$ in $\mathrm{HOL}), B-A 2-B(28.5 \%$ in $\mathrm{CHA}, 61.6 \%$ in BSW, and $40.1 \%$ in MON), $B-I-B(30.3 \%$ in NOR), $C-A 2-A(43.8 \%$ in $\mathrm{ABO})$, and $C-A 2-B(58.7 \%$ in JER and $32.8 \%$ in TAR). This reflected a high degree of diversity across breeds. We were able to distinguish 5 other casein haplotypes with a frequency $>9 \%$ in some breeds: $B-A 1-B$ in BLA (12.2\%), CHA (15.2\%), LIM $(17.8 \%), \operatorname{ABO}(14.6 \%)$ and TAR $(23.4 \%) ; B-A 1-C$ in TAR $(12.5 \%) ; B-A 1-E$ in HOL $(9.3 \%) ; B-B-A$ in MON (28.7\%); and $B-B-B$ in JER (12.9\%) and NOR (18.5\%). Finally, the $B-C-A, B-C-B$, and $C-A 3-A$ haplotypes were present at lower frequencies, in TAR (4.6\%), CHA (1.1\%), and NOR (1.5\%), respectively. The 6 other

Table 4. Percentages of casein haplotypes in 12 French cattle breeds ${ }^{1,2}$

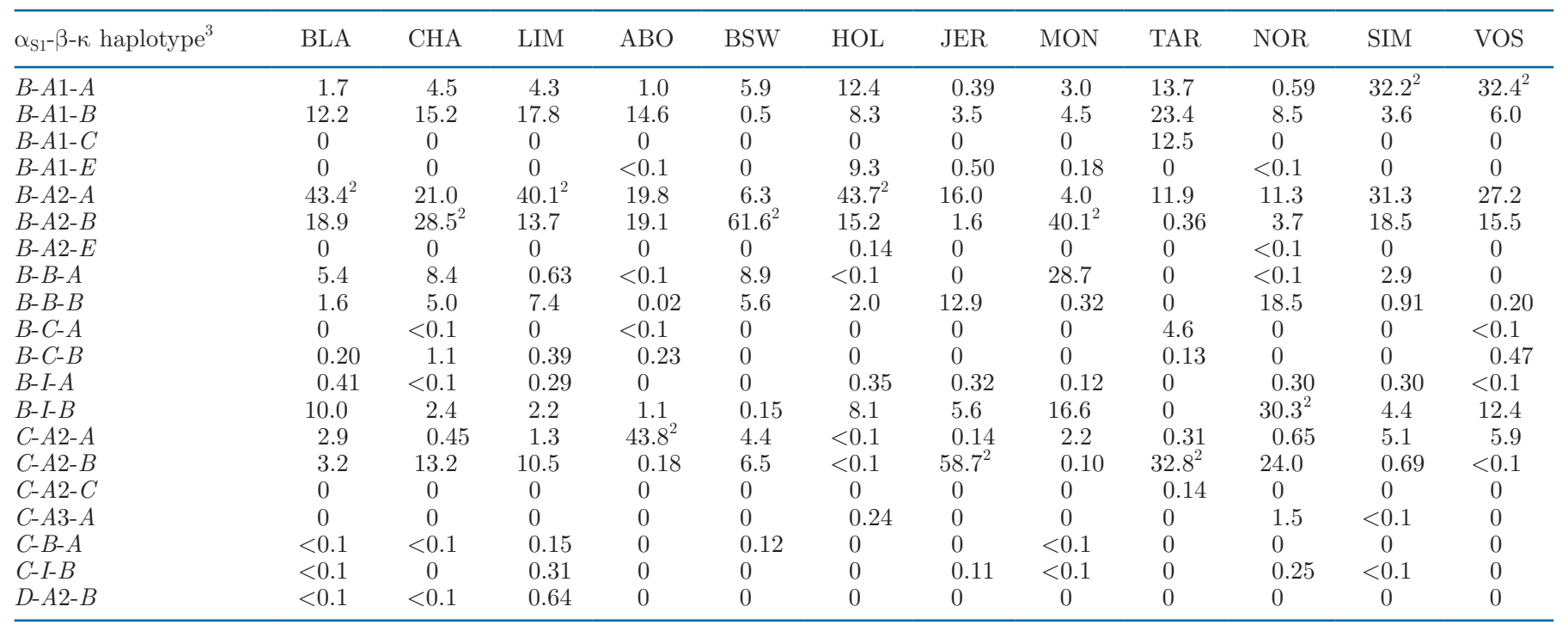

${ }^{1}$ Blonde d'Aquitaine (BLA), Charolaise (CHA), Limousine (LIM), Abondance (ABO), Brown Swiss (BSW), Holstein (HOL), Jersey (JER), Montbéliarde (MON), Tarentaise (TAR), Normande (NOR), Simmental (SIM), and Vosgienne (VOS).

${ }^{2}$ The most frequent haplotype for each breed.

${ }^{3}$ Only haplotypes found with a frequency $>0.1 \%$ in at least one breed were included. 
observed casein haplotypes had a frequency $<1 \%$ in all breeds.

\section{Trends of Protein Variant and Casein Haplotype Frequencies}

We estimated the trends of variant and casein haplotype frequencies in bulls and cows. In each breed, we calculated allele frequencies for every year in which at least 50 genotyped bulls or cows were born. For bulls, it was possible to follow the trend of frequencies since 1990 in the major breeds (HOL, MON, NOR, CHA, BLA, LIM, and SIM). In contrast, this analysis was much more limited for breeds of regional importance such as ABO (data available only since the 2000s), and TAR and VOS (2010s). With only 97 Jersey bulls genotyped, it was not possible to estimate any frequency trend in this breed (Appendix Figures A1, A2, A5, and A6). In all dairy breeds, the number of genotyped males was much lower than the number of genotyped females, and from 1990 to 2008, only progeny-tested bulls were genotyped. These limited numbers explain why frequencies were less stable for males than for females. As the birth years of genotyped cows spanned a more recent period, we were able to estimate frequencies only since the 2000s for all breeds, except JER (from 2015; Appendix Figures A3, A4, A5, and A6). In a given year, evolutionary patterns of protein variant and casein haplotype frequencies were similar between bulls and cows. A closer look at the HOL, MON, and NOR breeds, in which we observed the largest changes, is shown in Figure 2.

For $\beta$-LG, we observed different profiles among breeds. For the 3 beef breeds (BLA, CHA, and LIM), frequencies were relatively stable over time. In the other breeds for which we had enough informationHOL, MON, NOR, and SIM - the $B$ variant was more frequent than the $A$ variant until the mid-to-late 1990s, and then the frequencies either balanced out (NOR) or inverted (HOL, MON, and SIM).

For the past several decades, variant $B$ of $\alpha_{\mathrm{S1}^{-}} \mathrm{CN}$ has been largely predominant in all breeds (except in JER and to a lesser extent in $\mathrm{ABO}$ and TAR), and variant frequencies have been relatively stable over time.

The situation is more complex for $\beta-\mathrm{CN}$ because of the higher number of variants. The $A 2$ variant has been predominant for years in beef breeds (BLA, CHA, and LIM) as well as in the dairy breeds ABO and BSW. In other breeds, instead, variants other than $A 2$ have been relatively common for decades: variant $A 1$ in $\mathrm{HOL}$, TAR, SIM, and VOS and variants $B$ and $I$ in MON and NOR. In both MON and NOR, it is noteworthy that, starting around 2010, variant $B$ has tended to become less frequent in favor of variant $I$.
For $\kappa-\mathrm{CN}$, the situation is similar to that of $\beta$-LG: 2 main variants, $A$ and $B$, coexist in varying frequencies depending on the breed. Frequencies have been stable over time in most breeds with the exception of HOL and MON. In HOL, the $A$ variant was much more frequent than the $B$ variant in the $1980 \mathrm{~s}$, but the frequencies have gradually balanced out over time; today, $A$ and $B$ are present at similar frequencies. In contrast, in the MON breed, the $B$ variant is currently more frequent than $A$, but frequencies were more balanced before the 2000s.

Casein haplotype frequencies were relatively stable over time (Appendix Figures A5 and A6). However, we did observe an increase over the last $10 \mathrm{yr}$ in the frequencies of some casein haplotypes in certain breeds: $B-A 2-B$ in HOL and MON, $B-I-B$ in NOR and MON, and $C-A 2-A$ in $\mathrm{ABO}$.

\section{Breed Classification Based on Casein Haplotypes}

Figure 3 presents a classification of the breeds based on casein haplotype frequencies. The Oceanic group (JER and NOR) was clearly differentiated from the other breeds. The Hispanic group was also easily identified (LIM, BLA) and separated from the other breeds of Alpine and Central Europe origins, with CHA being intermediate. Among them, SIM and VOS and, separately, MON and BSW were very close to each other. However, based on this single locus, HOL and TAR positions were not in agreement with their geographical origins.

\section{DISCUSSION}

Here, we estimated the frequencies of milk protein variants and casein haplotypes in a sample of more than 1 million bulls and cows of 12 milk, dual-purpose, or beef French cattle breeds of Alpine, Northwest (Oceanic), or Southern (Iberic) origins. This large-scale study updated and built upon similar estimates that were obtained more than 30 yr ago in French breeds on proteins but with much smaller sample sizes (Grosclaude, 1988). To our knowledge, this study is the first of this magnitude, and it enables a long-term perspective of the trend of variant frequencies over the last few decades and over a large number of cattle breeds, which is crucial to appreciate the effects of selection. Beyond dairy breeds, this study also provides results in 3 beef breeds. Although these results are of limited practical importance, they help us interpret the effect of the geographical origins of the breeds and illustrate that beef breeds have greater genetic variability than dairy breeds. 

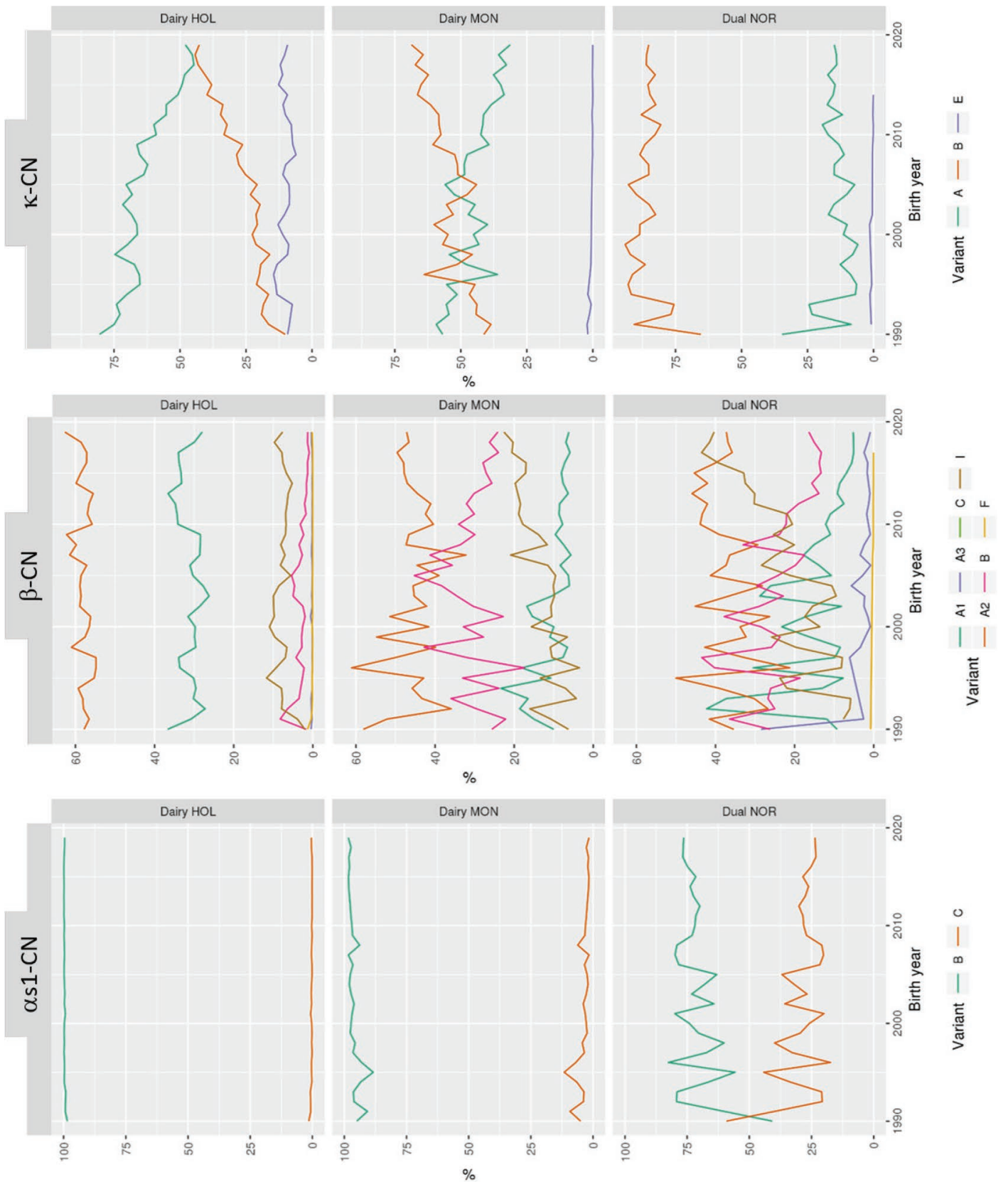

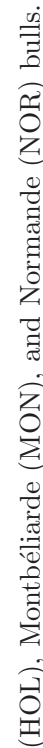
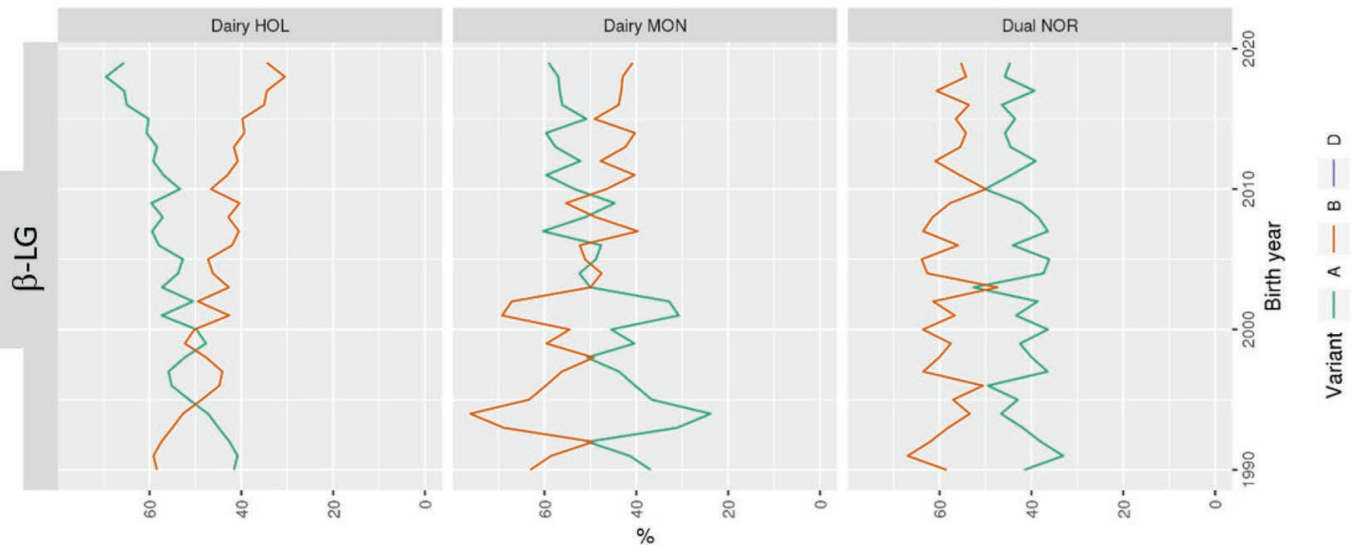


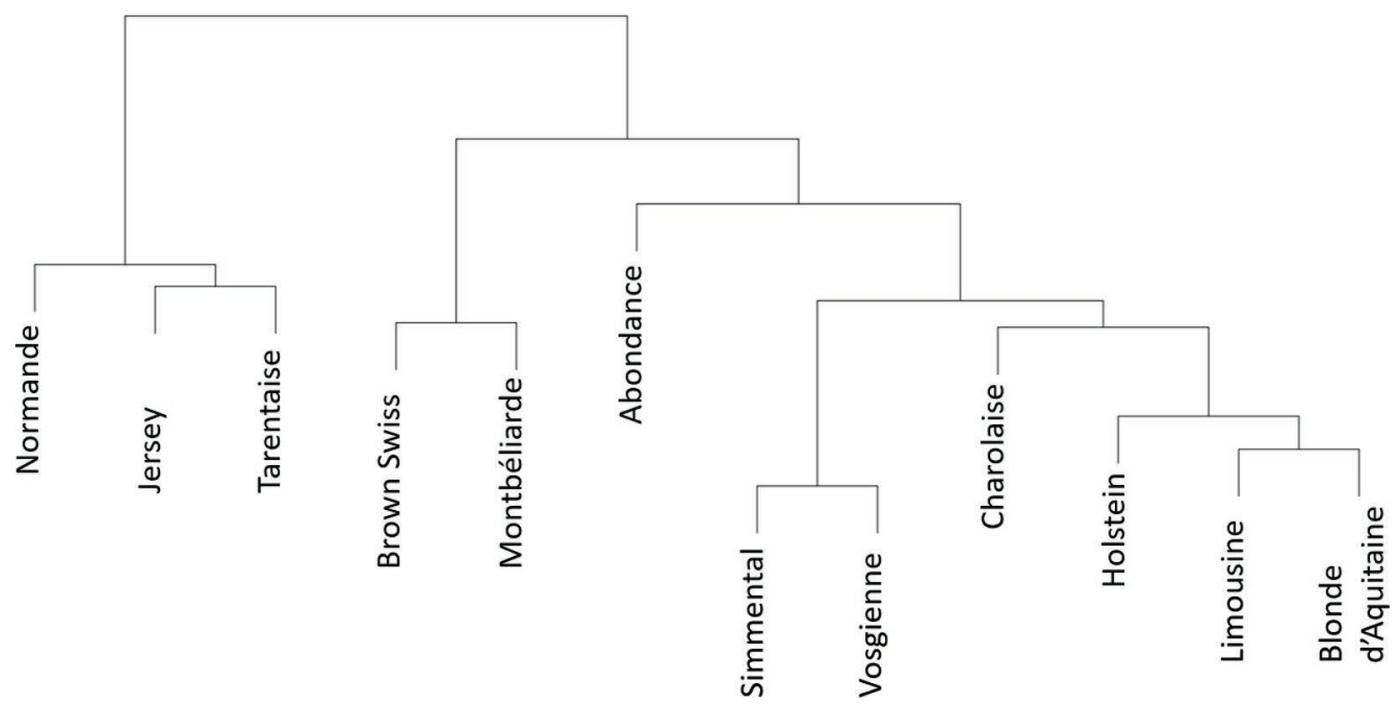

Figure 3. Cluster dendrogram based on all casein haplotypes in 12 French breeds.

The variant frequencies we estimated in the 12 breeds are consistent with those published in the review of Caroli et al. (2009), in which the variants $\beta-\mathrm{LG}-A$, $\beta-\mathrm{LG}-B, \quad \alpha_{\mathrm{S}^{-}} \mathrm{CN}-B, \beta-\mathrm{CN}-A 2, \kappa-\mathrm{CN}-A$, and $\kappa-\mathrm{CN}-B$ were described as the most common in Bos taurus based on multiple studies published between 1962 and 2002.

However, we also detected additional variants in $\beta$-CN $(I)$ and $\kappa-C N(C$ and $E)$ that were not identified in the study of Grosclaude (1988), although they probably already existed at that time.

The $\kappa_{-} \mathrm{CN}-C$ variant, which was specific to the Alpine TAR breed in our study, was first identified more than 40 yr ago in Grey Alpine cattle (Di Stasio and Merlin, 1979). This variant was also later described in TAR cows, at a frequency of $12 \%$ (Delacroix-Buchet et al., 1993), very close to the frequency we estimated here in the population of genotyped TAR animals $(5,573$ animals, $12.7 \%$ ). Because the genotyping in TAR was performed recently, it was not possible to estimate the trend of frequencies before 2006. Since 2006, however, the $\mathrm{\kappa}-\mathrm{CN}-C$ variant has been present in TAR at a relatively stable frequency; TAR was also the only breed in which the $D$ variant of $\kappa-C N$ was present. This variant is not caused by a specific mutation but instead results from the combination of the 2 mutations responsible for the $C$ and $A$ variants. The $D$ variant is rare and very likely originated from a recombination event between the 2 loci responsible for the $B$ and $C$ alleles, which are 153 bp apart. The $\kappa-C N-E$ variant was identified in the late 1980s in different breeds (Erhardt, 1989) but was almost exclusively found in the HOL breed in this study, with a stable frequency of nearly $10 \%$ since the 1980s. Its presence at low frequency in the MON breed likely originates from the limited HOL introgression in this breed. The $\beta$-CN- $I$ variant, which is derived from $A 2$, was discovered in the early 2000s in the Italian Red Pied (Jann et al., 2002) and here was found in almost all breeds. Its frequency has greatly increased in recent decades in MON (from 10 to 20\%), NOR (from 20 to $40 \%$ ), and BLA (from 4 to $15 \%$ ), but has remained relatively constant in the other breeds, including HOL $(\approx 8 \%)$. The $\beta-\mathrm{CN}-C$ variant, which is derived from $A 1$, was found at a frequency close to $5 \%$ in the TAR breed, whereas it was rare in the other breeds.

In addition to the emergence of some variants, we noted changes in the frequency of the most common variants. These changes were most marked in some dairy (HOL and MON) and dual-purpose (NOR and SIM) breeds; few changes were observed in beef breeds (BLA, CHA, and LIM). For the remaining dairy or dual-purpose breeds, it was more difficult to draw conclusions because we could not estimate variant frequencies before 2006 (ABO) or even 2015 (TAR, VOS, and JER) reliably.

Validity of conclusions about frequency trends depends on the representativeness of the genotyped animals over years. Old males were progeny-tested bulls who contributed to the initial reference population for genomic selection. For males born from 1990 to 2008, they included nearly all French progeny-tested bulls. Before 1990, the samples were smaller and often limited to elite bulls. Younger males born after 2008 were all candidates for genomic selection. Therefore, both old and recent males born after 1990 can be considered representative of their breed, in spite of their pedigreebased selection. For cows, the situation differed across breeds. In the common dairy breeds, only a small proportion of females were genotyped in the early years 
but many of them originated from research projects. Since 2013, genotyping for selection purposes has become much more common and generally on an entire herd. Therefore, the representativeness of the female sample is best in recent years but is good over the whole period. In beef breeds, the situation is similar, but with a 5-yr gap, as genomic selection started later in beef than in dairy breeds. Samples from males are likely to be representative, but this is more doubtful for females. In regional dairy breeds, the number of males in the sample pool is limited, whereas females with phenotypes were genotyped to build the reference population. Because of this, they can be considered representative of the entire breed.

Protein variants affect the concentrations of $\beta-\mathrm{LG}$ or caseins in milk, and some also modify the chemical properties of the proteins. Consequently, they have effects on the cheese-making abilities of milk, particularly on coagulation properties (time and firmness) and cheese yields (Ng-Kwai-Hang et al., 1986; Bovenhuis et al., 1992; Delacroix-Buchet et al., 1993; Ikonen et al., 1999; Caroli et al., 2000; Bonfatti et al., 2010). The $\beta-\mathrm{LG}-B$, $\alpha_{\mathrm{S} 1}-\mathrm{CN}-C, \beta-\mathrm{CN}-B, \beta-\mathrm{CN}-I$, and $\kappa-\mathrm{CN}-B$ variants were found to be associated with increased fat and casein contents in milk, and therefore, with better cheesemaking traits (Ng-Kwai-Hang et al., 1986; Bovenhuis et al., 1992; Delacroix-Buchet et al., 1993; Bonfatti et al., 2010). In contrast, the $\beta-\mathrm{LG}-A, \alpha_{\mathrm{S} 1}-\mathrm{CN}-B, \kappa-\mathrm{CN}-A$, and $\kappa-\mathrm{CN}-E$ variants have positive effects on milk yield but adverse effects on milk composition and cheesemaking traits. The $\beta-\mathrm{CN}-C$ variant is very detrimental for cheese-making properties (Delacroix-Buchet and Marie, 1994). The effects of the variants may therefore explain some of the changes in frequencies over time that we observed. For example, we found increases in the frequencies of the favorable variants $\beta-\mathrm{CN}-I$ and $\kappa-\mathrm{CN}-B$ mainly in breeds that have been selected for milk composition. In contrast, the frequency of variant $\beta$-LG- $B$ decreases over time in the HOL, MON, and NOR dairy breeds in favor of variant $A$, which is responsible for milk with poorer cheese-making ability. Previous studies have shown that an increase in $\beta-L G$ content (as a percentage of total protein content in milk), which is caused by variant $A$, is counterbalanced by a relative decrease in caseins, particularly $\alpha_{\mathrm{S}_{1}} \mathrm{CN}$ and $\beta-\mathrm{CN}$, which are the most abundant caseins in bovine milk (Ng-Kwai-Hang et al., 1987; Heck et al., 2009). This decrease in casein content likely explains the adverse effect of variant $A$ on the cheese-making properties of milk. Other studies found that genotype $A A$ had favorable effects on milk and protein yields (Bovenhuis et al., 1992; Ikonen et al., 1999), which could explain why variant $A$ of $\beta-\mathrm{LG}$ has been selected in some major dairy breeds.
As the imputation process involves phasing, construction of haplotypes was straightforward. This procedure is very accurate, especially with the strong family structure of cattle breeds and with the very low rate of recombination among the 15 loci in the casein region that were studied here. Although we observed a large diversity of protein variants and casein haplotypes across breeds, we found only 20 casein haplotypes out of 90 possible combinations. Of these, only 14 were found at a frequency $>1 \%$ in at least one breed, and only 6 to 9 were found in each breed. Of the haplotype combinations that were present in each breed, 5 were the most frequent haplotypes in at least one breed $(B-A 2-A$, $B$ - $A 2-B, B-I-B, C-A 2-A$, and $C-A 2-B)$. The low number of haplotypes and the strong linkage disequilibrium between casein variants is mainly due to the vicinity of casein genes to each other on the genome, which results in the co-transmission of casein gene variants across generations and in a low rate of recombination between them. Grosclaude (1988) estimated casein haplotype frequencies in HOL, MON, NOR, and TAR cattle; in that study, $B-A 2-A$ was the most frequent haplotype in HOL (37\%), MON (31\%), and TAR (30\%), whereas $B-B-B$ was predominant in NOR $(45 \%)$. Our analysis revealed very different results for the MON, NOR, and TAR breeds: the most frequent casein haplotypes from the 1980s are no longer the main haplotypes, which are now $B-A 2-B, B-I-B$, and $C-A 2-B$, respectively. However, the $B-A 2-A$ haplotype is still the most frequent in HOL (44\%). It therefore seems that there is now a greater diversity of major casein haplotypes among breeds than in the past, partly due to the emergence of some new casein variants. The recent discovery of certain variants (such as $\beta-\mathrm{CN}-I$ ) also partly explains this finding.

The $\kappa-\mathrm{CN}-E$ variant, which was found at its highest frequency in HOL, is mainly associated with the $\alpha_{\mathrm{S}^{-}}$ $\mathrm{CN}-B$ and $\beta-\mathrm{CN}-A 1$ variants, which together form the $B$ - $A 1-E$ haplotype. The frequency of the $E$ variant has been quite stable since the $90 \mathrm{~s}$, which is likely linked to the fact that in those years the goal of selection was changed (lower weight given to milk production in favor of improvements to milk composition). Similarly, the $\kappa-\mathrm{CN}-C$ variant, which is found almost exclusively in TAR, is mainly associated with the $\alpha_{\mathrm{S} 1}-\mathrm{CN}-C$ and $\beta-\mathrm{CN}-A 2$ variants to form the $C-A 2-C$ haplotype. Likewise, variant $I$ of $\beta$-CN is almost completely associated with the $B$ variants of the other 2 casein genes to form the $B-I-B$ casein haplotype. The $C$ variant of $\beta-C N$ is always associated with the $B$ variant of $\alpha_{\mathrm{S} 1}-\mathrm{CN}$ and, in most breeds, with variant $B$ of $\kappa-\mathrm{CN}$ to form the $B$ - $C$ - $B$ haplotype, with the exception of the TAR breed, in which the $B-C-A$ haplotype is much more frequent.

One locus, even a very polymorphic one, is not sufficient for estimating genetic distances among breeds. 
However, some patterns of similarity that we detected in the milk proteins (Figure 3) are consistent with the known origins of the breeds (Grosclaude et al., 1990; Jann et al., 2002). For instance, both the JER and NOR, breeds that originate in the English Channel area, have a high proportion of the $C-A 2-B$ haplotype. Both BLA and LIM, which have Iberic origins and are known to be closely related, have a high frequency of $B-A 2-A$. The SIM and VOS breeds, from Central Europe, share similar haplotype profiles, with high frequencies of $B-A 1-A, B-A 2-A$, and $B-A 2-B$. The MON and BSW breeds, of Alpine origin, have the same 2 predominant haplotypes, $B-A 2-B$ and $B-B-A$. Nevertheless, we did find exceptions, as shown by the large degree of genetic diversity in the 6 Central European and Alpine breeds. The HOL breed appears to be unique in harboring the $E$ variant of $\kappa-\mathrm{CN}$ and shares some similarities with all groups of breeds, especially in having a high frequency of $B-A 2-A$, like the Iberic breeds. This classification based on only one locus can be compared with that of Gautier et al. (2010) based on 44,706 SNPs spanning the whole genome. Although the classifications agree quite well, results were highly different for 2 breeds, HOL and TAR. In Gautier et al. (2010), TAR is grouped with Alpine breeds, whereas HOL belongs to another group not studied here.

Some studies have suggested that certain milk protein variants have effects on human health. In particular, it has been claimed that the $\beta-\mathrm{CN}-A 2$ allele is better tolerated in some parts of the human population (He et al., 2017). Although the relationship between $A 1$ bovine milk consumption and human disease incidence has not been confirmed, some recommendations have appeared worldwide to increase the frequency of variant $A 2$. A similar health effect could also be obtained with any variant of the $A 2$ family; that is, those with a proline at position 67 (variants $A 2, A 3, E, D, I, J, H$ ). Because $I$ is frequent in some breeds (HOL, MON, and especially NOR), should $A 2$ be selected, including $I$ allele in selection decision would provide faster results without wasting genetic variability. However, due to the strong linkage disequilibrium between variants of caseins, it is important to note that an increase in the frequency of variant $A 2$ of $\beta-\mathrm{CN}$ will also induce increases in the frequencies of certain variants of $\alpha_{\mathrm{S} 1}-\mathrm{CN}$ and $\kappa-\mathrm{CN}$. Our results indicate that selecting for the $A 2$ variant would also increase the frequency of the $C$ variant of $\alpha_{\mathrm{S}_{1}} \mathrm{CN}$ in ABO, JER, TAR, and NOR, and of the $A$ variant of $\kappa-\mathrm{CN}$ in $\mathrm{HOL}$ and $\mathrm{ABO}$, both of which have unfavorable effects on the cheese-making properties of milk. These results illustrate the "hitchhiking" phenomenon: when directly selecting for some alleles, the response to selection modifies the neighboring region due to the haplotypic structure of the genome and linkage disequilibrium (Smith and Haigh, 1974). Generally, geneticists do not recommend direct selection on individual genes because they frequently explain a limited part of the variability of the major traits. Should selection be based on individual genes, it would be preferable to include this information in a total merit index (Segelke et al., 2016). If breeders want to select for some casein variants, we strongly recommend defining the objective in term of haplotypes instead of individual variants. Even if these variants are not directly selected, detailed and continuous monitoring is of interest to make breeders aware of the frequency changes induced by selection and the resultant consequences on milk properties.

\section{CONCLUSIONS}

The expansion of genomic selection and large-scale genotyping provides us with new opportunities to revisit milk protein variant frequencies that can now be studied at a much larger scale. The use of custom SNP chips enables the study of targeted variants of interest and, with the imputation and phasing of genotypes now being routine, genotypes and haplotypes of these variants can be recovered for any genotyped animal. The approach used here can be applied to any variant or haplotype as soon as it is included in the SNP genotyping chips. Here we provide frequencies of milk protein variants and casein haplotypes from large populations of a wide range of French cattle breeds raised for different objectives (milk, dual-purpose, or even beef) and of different origins (Oceanic, Alpine and Iberic). With these results, we updated and built upon values estimated more than $30 \mathrm{yr}$ ago and, for the first time in these breeds, we can assess the effect of indirect selection on milk protein variants. In the 2 major dairy breeds (HOL and MON), we observed a clear increasing trend in frequency of the $A$ allele of $\beta-\mathrm{LG}$ and the $B$ allele of the $\kappa-\mathrm{CN}$. If the first is likely due to the selection for milk yield, the latter was not expected and may have different origins, including selection for milk protein content or direct selection on this allele. The $I$ allele of the $\beta-\mathrm{CN}$ also showed increasing frequency in MON and NOR. These changes in frequencies may have major effects on milk properties. From haplotype information, we were able to predict the effect of selection for some alleles on other variants. In particular, we noted a clear risk of reducing $\kappa-\mathrm{CN}-B$ frequency (favorable to cheese-making properties) when selecting for $\beta-\mathrm{CN}-A 2$ in Holstein. Finally, detailed and continuous monitoring of milk protein genes is important to make breeders aware of the frequency changes induced by selection, with their consequences on milk properties. 


\section{ACKNOWLEDGMENTS}

The authors warmly acknowledge all the farmers, breeding organizations, and breeding companies that have contributed to the French national bovine genotype database (SIGENO). The authors declare that they have no conflict of interest.

\section{REFERENCES}

Aschaffenburg, R., and J. Drewry. 1957. Genetics of the beta-lactoglobulins of cows milk. Nature 180:376-378. https://doi.org/10 $.1038 / 180376 \mathrm{a} 0$.

Boichard, D., M. Boussaha, A. Capitan, D. Rocha, C. Hozé, M. P. Sanchez, T. Tribout, R. Letaief, P. Croiseau, C. Grohs, W. Li, C. Harland, C. Charlier, M. S. Lund, G. Sahana, M. Georges, S. Barbier, W. Coppieters, S. Fritz, and B. Guldbrandtsen. 2018. Experience from large scale use of the EuroGenomics custom SNP chip in cattle. In Proc. World Congr. Genet. Appl. Livest. Prod., Auckland, New Zealand, Volume Molecular Genetics 4:11.675.

Boichard, D., F. Guillaume, A. Baur, P. Croiseau, M. Rossignol, M. Boscher, T. Druet, L. Genestout, J. Colleau, L. Journaux, V. Ducrocq, and S. Fritz. 2012. Genomic selection in French dairy cattle. Anim. Prod. Sci. 52:115-120. https://doi.org/10.1071/AN11119.

Bonfatti, V., G. Di Martino, A. Cecchinato, D. Vicario, and P. Carnier. 2010. Effects of beta-kappa-casein (CSN2-CSN3) haplotypes and beta-lactoglobulin (BLG) genotypes on milk production traits and detailed protein composition of individual milk of Simmental cows. J. Dairy Sci. 93:3797-3808. https://doi.org/10.3168/jds.2009 -2778 .

Bovenhuis, H., J. Van Arendonk, and S. Korver. 1992. Associations between milk protein polymorphisms and milk-production traits. J. Dairy Sci. 75:2549-2559. https://doi.org/10.3168/jds.S0022 -0302(92)78017-5.

Caroli, A., P. Bolla, E. Budelli, G. Barbieri, and P. Leone. 2000. Effect of k-casein E allele on clotting aptitude of Italian Friesian milk. Zootec. Nutr. Anim. 3:127-130.

Caroli, A. M., S. Chessa, and G. J. Erhardt. 2009. Invited review: Milk protein polymorphisms in cattle: Effect on animal breeding and human nutrition. J. Dairy Sci. 92:5335-5352. https://doi.org/10 $.3168 /$ jds.2009-2461.

Delacroix-Buchet, A., D. Lefier, and V. Nuyts-Petit. 1993. «-Casein polymorphisms and milk rennet coagulation ability. Lait 73:61-72. https://doi.org/10.1051/lait:199313.

Delacroix-Buchet, A., and C. Marie. 1994. b-Casein C and Beaufort type cheese production. Lait 74:343-360. https://doi.org/10.1051/ lait:1994529.

Di Stasio, L., and P. Merlin. 1979. Polimorfismi biochimici del latte nella razza bovina Grigio Alpina. Riv. Zoot. Vet. 2:64-67.

Erhardt, G. 1989. K-Caseins in bovine-milk-Evidence of a further allele (K-CNE) in different breeds. J. Anim. Breed. Genet. 106:225231. https://doi.org/10.1111/j.1439-0388.1989.tb00233.x.

Farrell, H. M. Jr., R. Jimenez-Flores, G. Bleck, E. Brown, J. Butler, L. Creamer, C. Hicks, C. Hollar, K. Ng-Kwai-Hang, and H. Swaisgood. 2004. Nomenclature of the proteins of cows' milk-Sixth revision. J. Dairy Sci. 87:1641-1674. https://doi.org/10.3168/jds .S0022-0302(04)73319-6.

Gautier, M., D. Laloe, and K. Moazami-Goudarzi. 2010. Insights into the genetic history of French cattle from dense SNP data on 47 worldwide breeds. PLoS One 5:e13038. https://doi.org/10.1371/ journal.pone.0013038.

Grosclaude, F. 1988. Le polymorphisme génétique des principales lactoprotéines bovines. INRA Prod. Anim. 1:5-17.

Grosclaude, F., R. Aupetit, J. Lefebvre, and J. Meriaux. 1990. Tentative analysis of genetic-relationship between French cattle breeds using biochemical polymorphism. Genet. Sel. Evol. 22:317-338. https://doi.org/10.1186/1297-9686-22-3-317.
He, M., J. Sun, Z. Jiang, and Y. Yang. 2017. Effects of cow's milk beta-casein variants on symptoms of milk intolerance in Chinese adults: A multicentre, randomised controlled study. Nutr. J. 16:72. https://doi.org/10.1186/s12937-017-0275-0.

Heck, J. M., A. Schennink, H. van Valenberg, H. Bovenhuis, M. Visker, J. van Arendonk, and A. van Hooijdonk. 2009. Effects of milk protein variants on the protein composition of bovine milk. J. Dairy Sci. 92:1192-1202. https://doi.org/10.3168/jds.2008-1208.

Ikonen, T., M. Ojala, and O. Ruottinen. 1999. Associations between milk protein polymorphism and first lactation milk production traits in Finnish Ayrshire cows. J. Dairy Sci. 82:1026-1033. https: //doi.org/10.3168/jds.S0022-0302(99)75323-3.

Jann, O., G. Ceriotti, A. Caroli, and G. Erhardt. 2002. A new variant in exon VII of bovine beta-casein gene (CSN2) and its distribution among European cattle breeds. J. Anim. Breed. Genet. 119:65-68. https://doi.org/10.1046/j.1439-0388.2002.00318.x.

Martin, P., M. Szymanowska, L. Zwierzchowski, and C. Leroux. 2002. The impact of genetic polymorphisms on the protein composition of ruminant milks. Reprod. Nutr. Dev. 42:433-459. https://doi .org/10.1051/rnd:2002036.

Meier, S., P. Korkuc, D. Arends, and G. Brockmann. 2019. DNA sequence variants and protein haplotypes of casein genes in German Black Pied cattle (DSN). Front. Genet. 10:1129. https://doi.org/ 10.3389/fgene.2019.01129.

Müllner, D. 2013. Fast hierarchical, agglomerative clustering routines for R and Python. J. Stat. Softw. 53:1-18. https://doi.org/10 $.18637 /$ jss.v053.i09.

Ng-Kwai-Hang, K. F., J. Hayes, J. Moxley, and H. Monardes. 1984. Association of genetic variants of casein and milk serum proteins with milk, fat, and protein production by dairy cattle. J. Dairy Sci. 67:835-840. https://doi.org/10.3168/jds.S0022-0302(84)81374-0.

Ng-Kwai-Hang, K. F., J. Hayes, J. Moxley, and H. Monardes. 1986. Relationships between milk protein polymorphisms and major milk constituents in Holstein-Friesian cows. J. Dairy Sci. 69:22-26. https://doi.org/10.3168/jds.S0022-0302(86)80364-2.

Ng-Kwai-Hang, K. F., J. Hayes, J. Moxley, and H. Monardes. 1987. Variation in milk protein concentrations associated with genetic polymorphism and environmental factors. J. Dairy Sci. 70:563570. https://doi.org/10.3168/jds.S0022-0302(87)80042-5.

Saintilan, R., A. Capitan, M. Benoit, S. Barbier, and S. Fritz. 2014 Développement d'un outil génomique de présélection sur aptitudes bouchères et facilité de naissance en races Charolaise, Limousine et Blonde d'Aquitaine. Pages 241-244 in Rencontres Recherche Ruminants. Vol. 21, Paris, France.

Sanchez, M.-P., D. Jonas, A. Baur, V. Ducrocq, C. Hozé, R. Saintilan, F. Phocas, S. Fritz, D. Boichard, and P. Croiseau. 2016. Mise en place d'une évaluation génomique en races Abondance, Tarentaise et Vosgienne. Page 157 in Rencontres Recherche Ruminants. Vol. 23, Paris, France.

Sargolzaei, M., J. P. Chesnais, and F. S. Schenkel. 2014. A new approach for efficient genotype imputation using information from relatives. BMC Genom. 15:478. https://doi.org/10.1186/1471 $-2164-15-478$.

Segelke, D., H. Taubert, F. Reinhardt, and G. Thaller. 2016. Considering genetic characteristics in German Holstein breeding programs. J. Dairy Sci. 99:458-467. https://doi.org/10.3168/jds.2015-9764.

Smith, J. M., and J. Haigh. 1974. The hitch-hiking effect of a favourable gene. Genet. Res. 23:23-35. https://doi.org/10.1017/ S0016672300014634.

\section{ORCIDS}

M. P. Sanchez @ https://orcid.org/0000-0002-1371-5342

A. Delacroix-Buchet (ㄴ) https://orcid.org/0000-0002-8065-560X

D. Boichard ๑ https://orcid.org/0000-0003-0361-2961 


\section{APPENDIX}

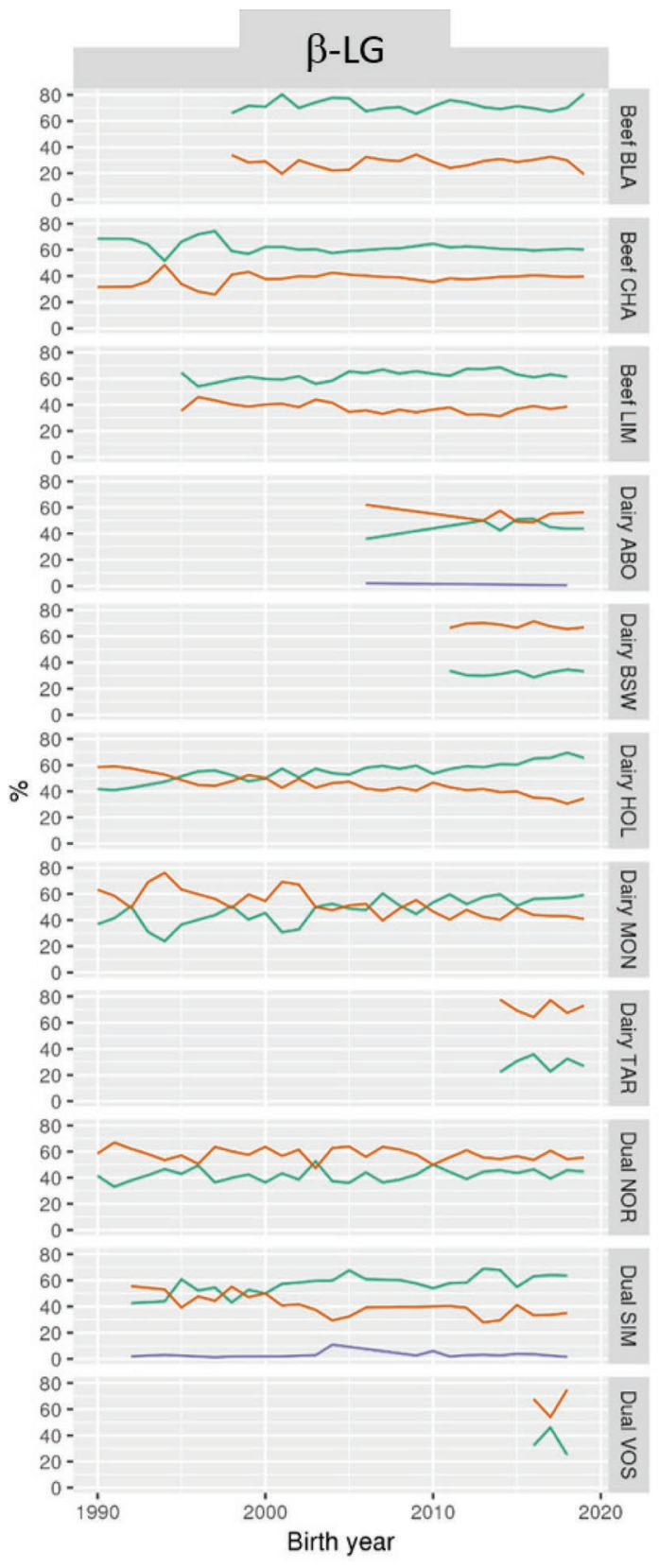

Variant $-A-B-D$

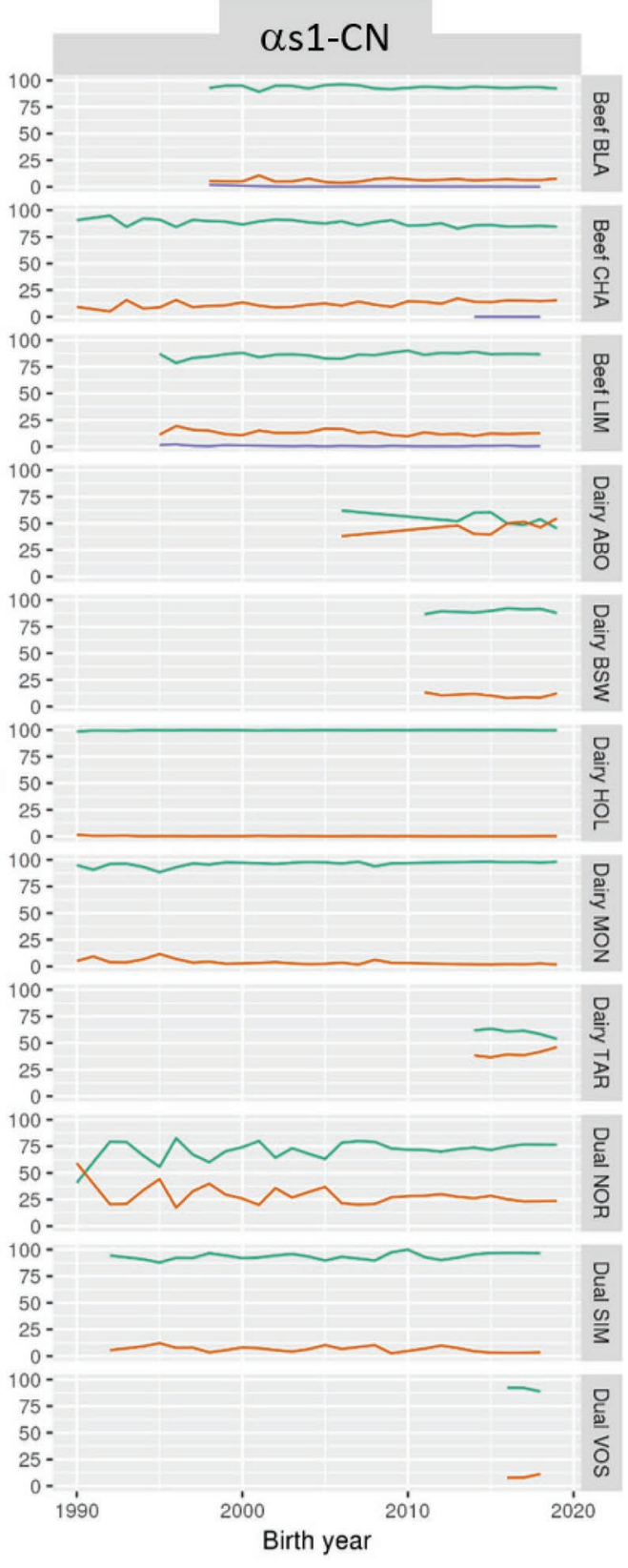

Variant $-\mathrm{B}-\mathrm{C}-\mathrm{D}$

Figure A1. Trends of the frequencies (\%) of $\beta-\mathrm{LG}$ and $\alpha_{\mathrm{S} 1}-\mathrm{CN}$ variant alleles in bulls. Blonde d'Aquitaine (BLA), Charolaise (CHA), Limousine (LIM), Abondance (ABO), Brown Swiss (BSW), Holstein (HOL), Montbéliarde (MON), Tarentaise (TAR), Normande (NOR), Simmental (SIM), and Vosgienne (VOS). 

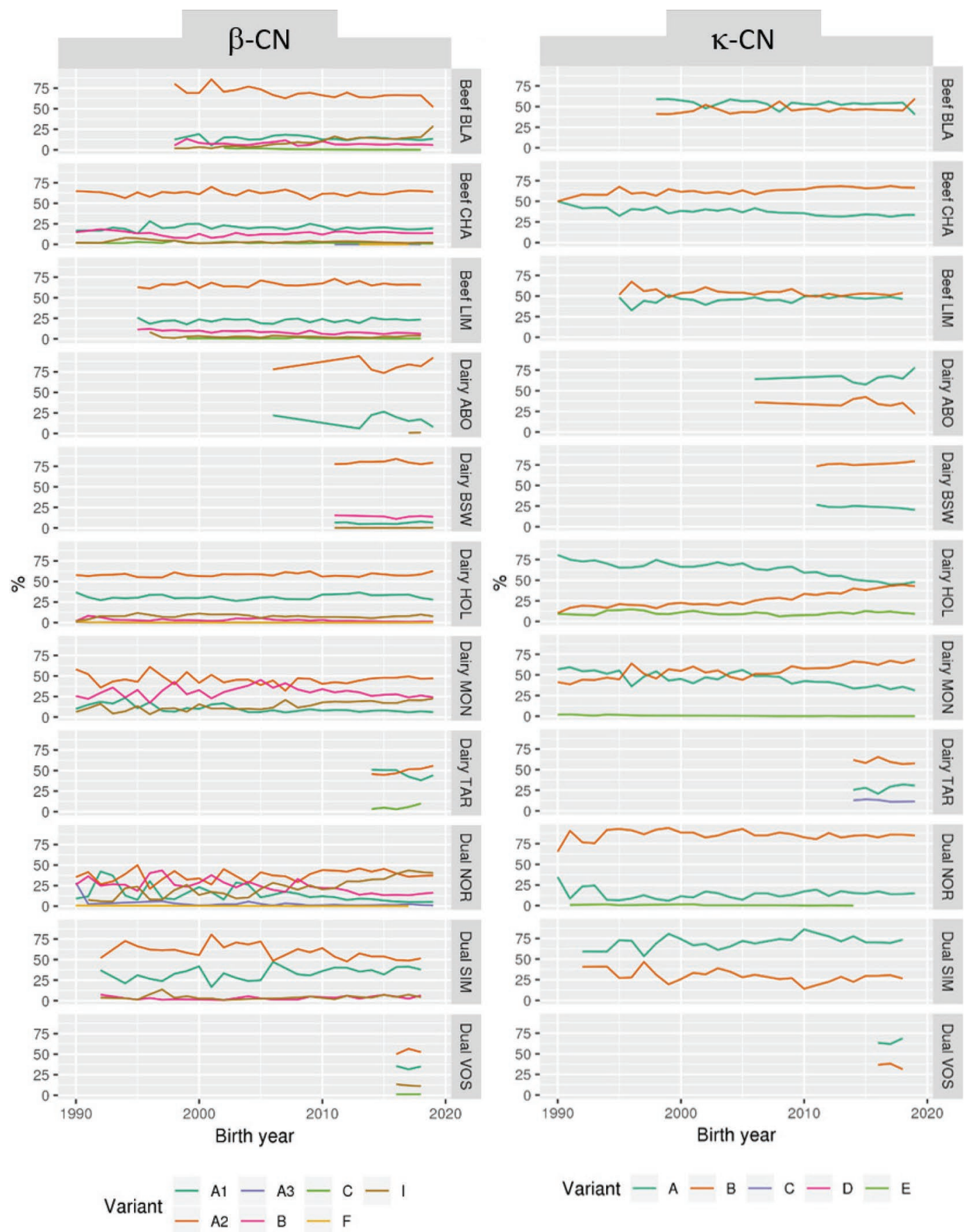

Variant $-\mathrm{A}-\mathrm{B}-\mathrm{C}-\mathrm{D}-\mathrm{E}$

Figure A2. Trends of the frequencies (\%) of $\beta-\mathrm{CN}$ and $\kappa-\mathrm{CN}$ variant alleles in bulls. Blonde d'Aquitaine (BLA), Charolaise (CHA), Limousine (LIM), Abondance (ABO), Brown Swiss (BSW), Holstein (HOL), Montbéliarde (MON), Tarentaise (TAR), Normande (NOR), Simmental (SIM), and Vosgienne (VOS). 


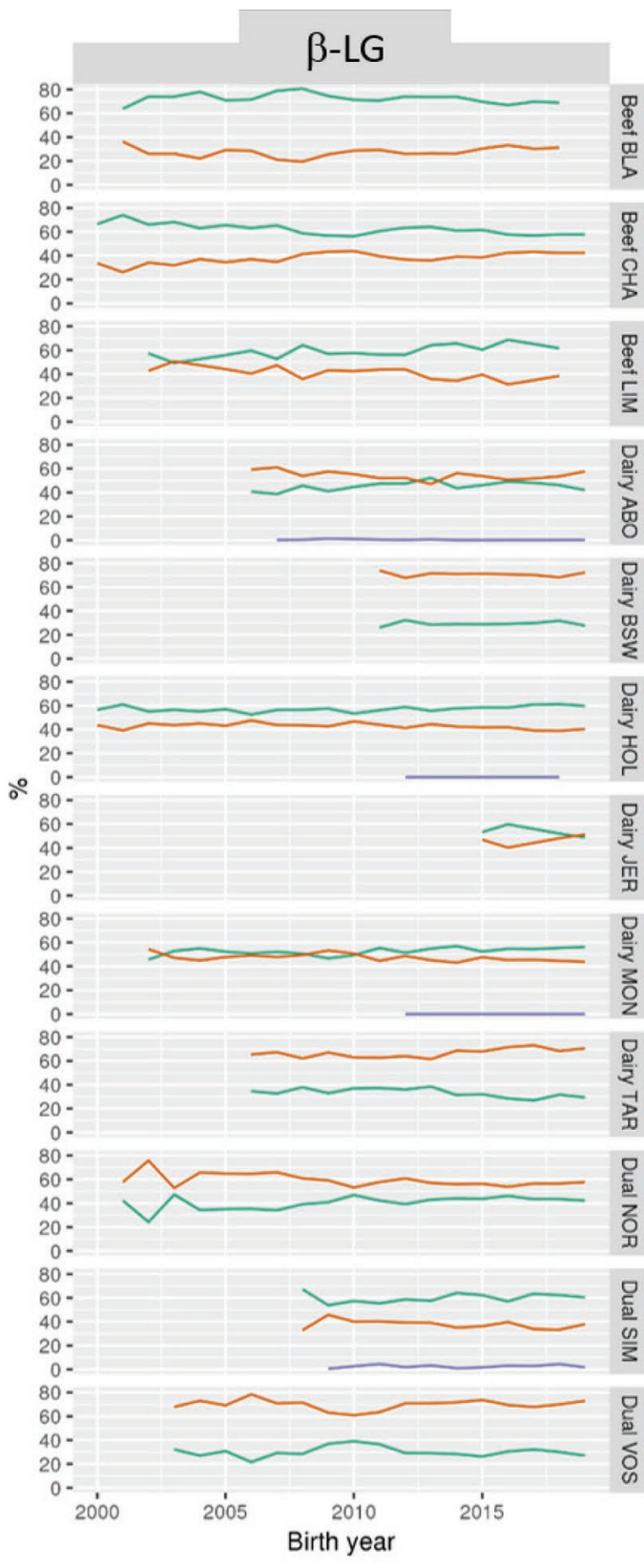

Variant $-\mathrm{A}-\mathrm{B}-\mathrm{D}$

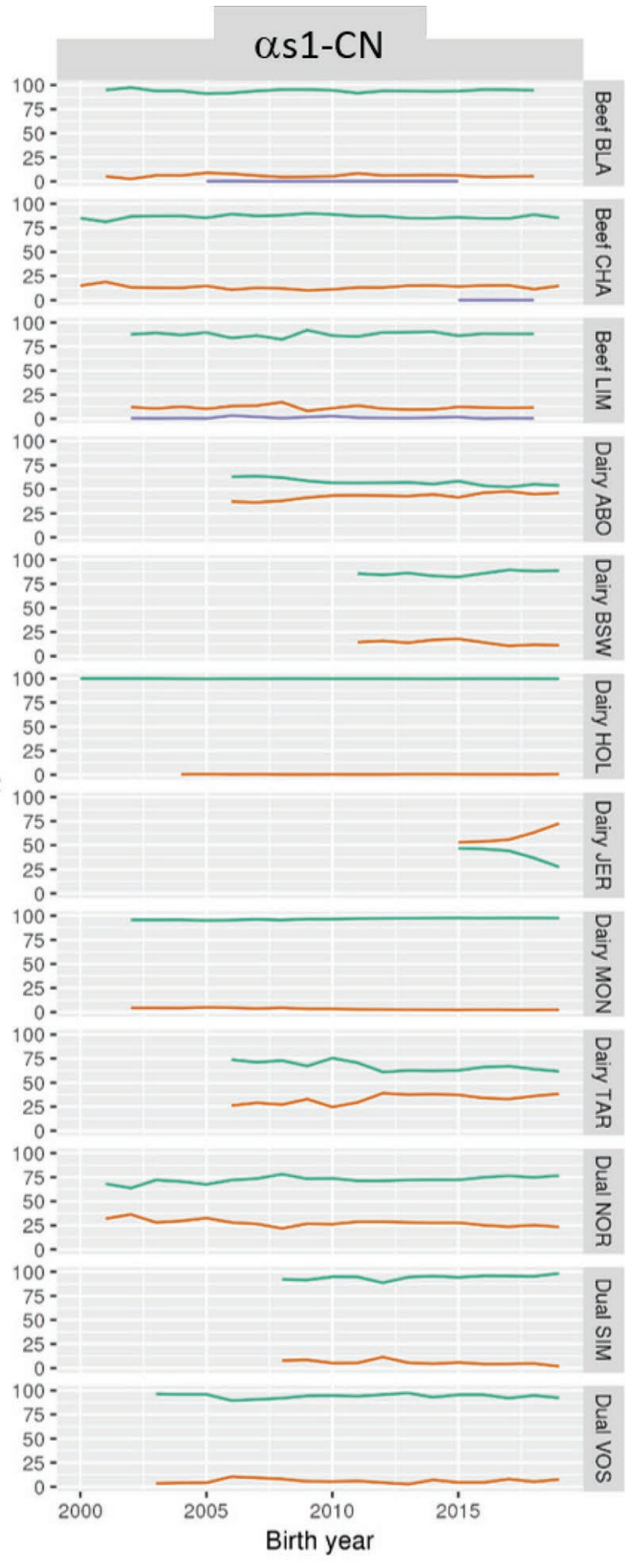

Variant $-\mathrm{B}-\mathrm{C}-\mathrm{D}$

Figure A3. Trends of the frequencies (\%) of $\beta-\mathrm{LG}$ and $\alpha_{\mathrm{S1}^{-}} \mathrm{CN}$ variant alleles in cows. Blonde d'Aquitaine (BLA), Charolaise (CHA), Limousine (LIM), Abondance (ABO), Brown Swiss (BSW), Holstein (HOL), Jersey (JER), Montbéliarde (MON), Tarentaise (TAR), Normande (NOR), Simmental (SIM), and Vosgienne (VOS). 

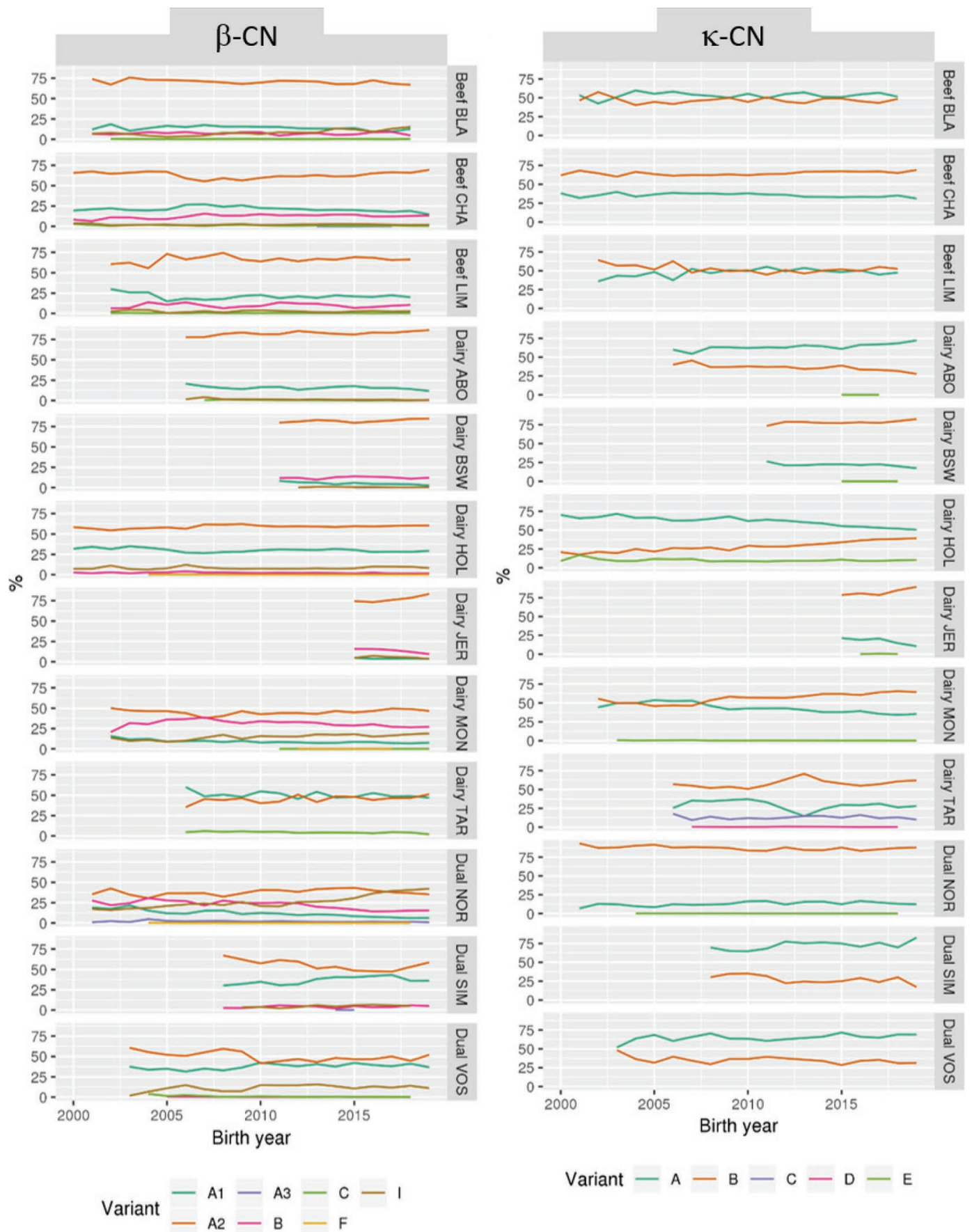

Figure A4. Trends of the frequencies $(\%)$ of $\beta-\mathrm{CN}$ and $\kappa-\mathrm{CN}$ variant alleles in cows. Blonde d'Aquitaine (BLA), Charolaise (CHA), Limousine (LIM), Abondance (ABO), Brown Swiss (BSW), Holstein (HOL), Jersey (JER), Montbéliarde (MON), Tarentaise (TAR), Normande (NOR), Simmental (SIM), and Vosgienne (VOS) 


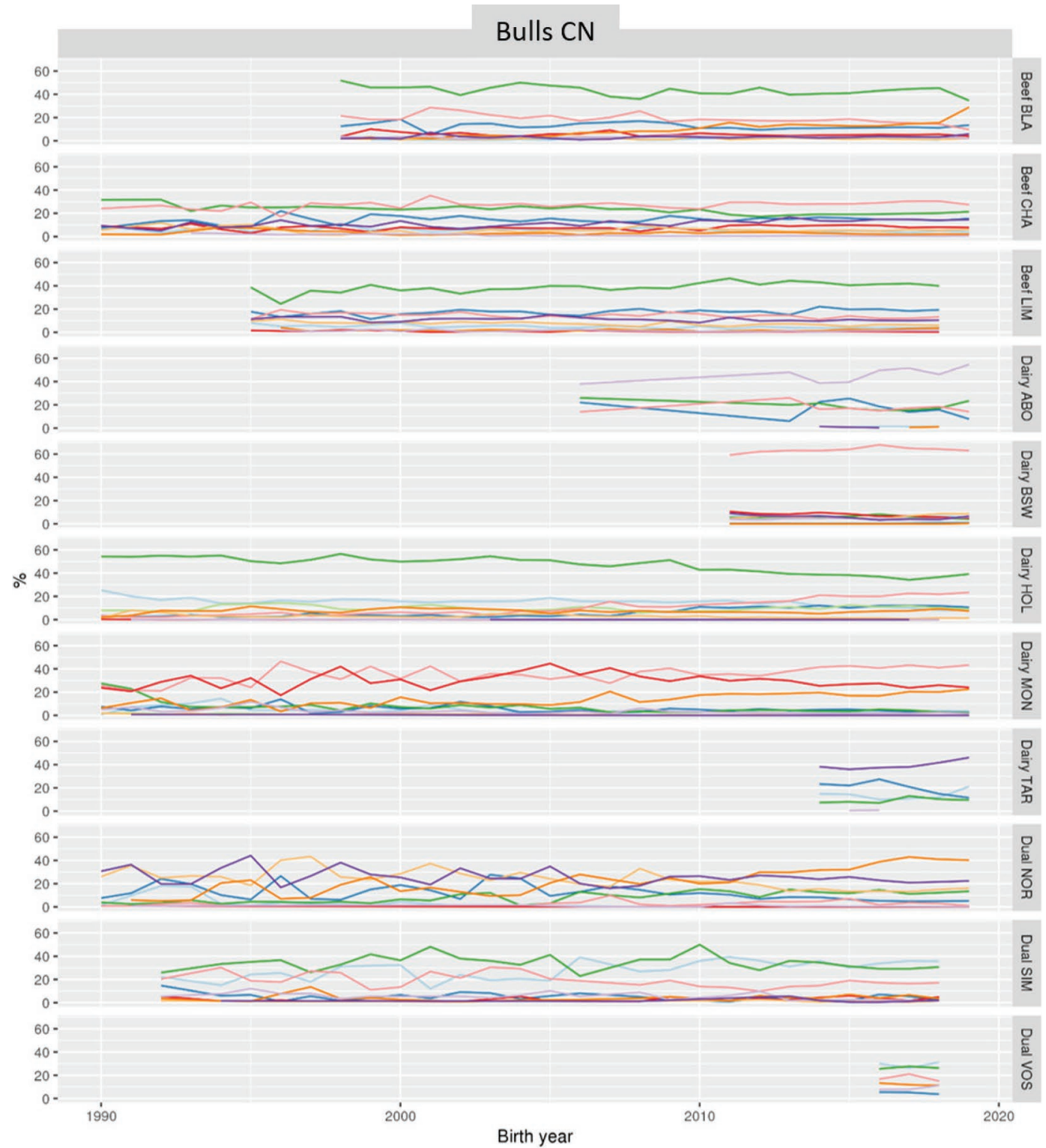

$$
\begin{aligned}
& \text { Haplotype } \\
& - \text { B-A1-A }- \text { B-B-A } \\
& - \text { B-A1-B }- \text { B-B-B } \\
& - \text { B-A1-E }- \text { B-1-B } \\
& - \text { B-A2-A }- \text { C-A2-A } \\
& - \text { B-A2-B }- \text { C-A2-B }
\end{aligned}
$$

Figure A5. Trends of casein haplotype frequencies (\%) in bulls. Blonde d'Aquitaine (BLA), Charolaise (CHA), Limousine (LIM), Abondance (ABO), Brown Swiss (BSW), Holstein (HOL), Montbéliarde (MON), Tarentaise (TAR), Normande (NOR), Simmental (SIM), and Vosgienne (VOS). 


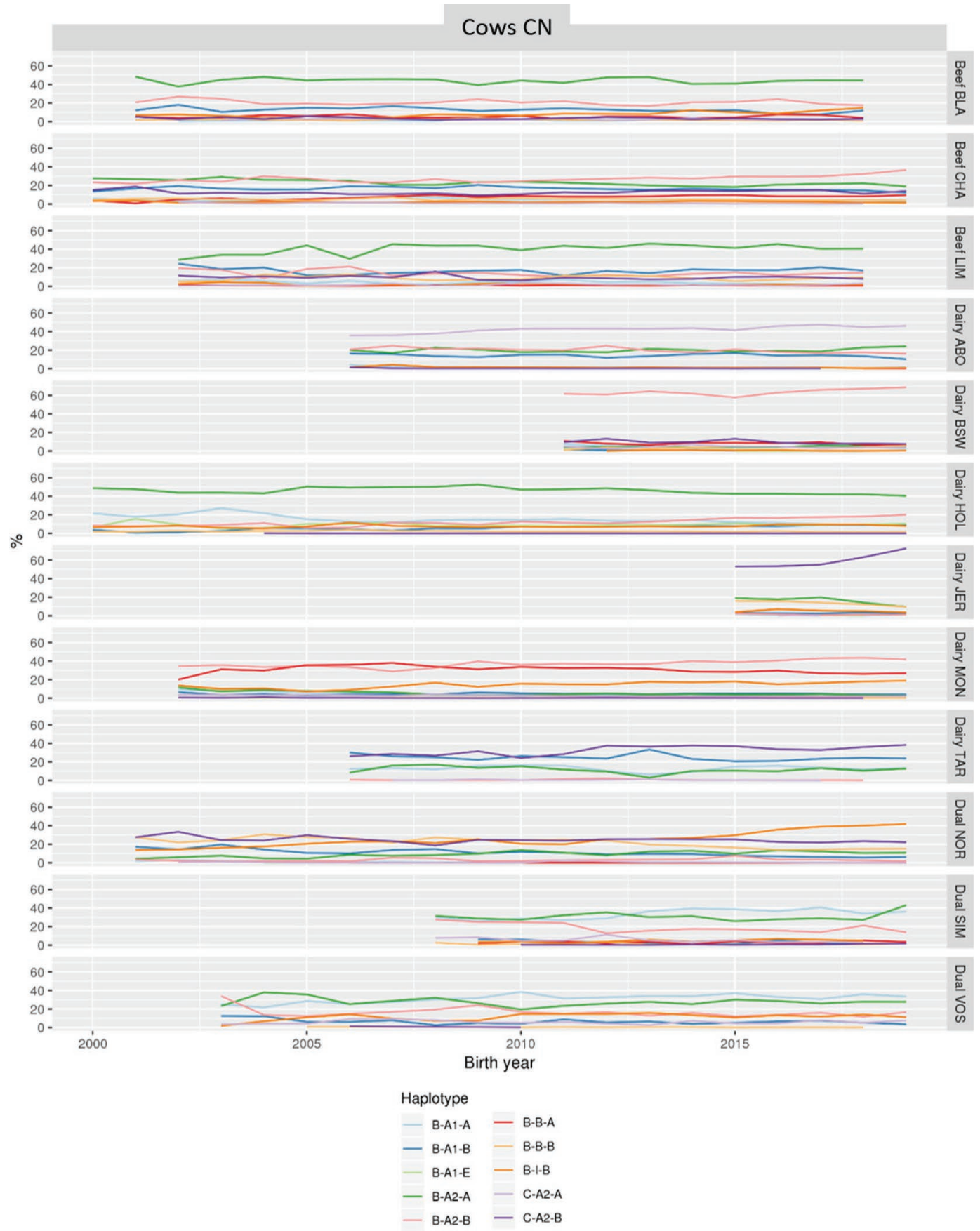

Figure A6. Trends of casein haplotype frequencies (\%) in cows. Blonde d'Aquitaine (BLA), Charolaise (CHA), Limousine (LIM), Abondance (ABO), Brown Swiss (BSW), Holstein (HOL), Jersey (JER), Montbéliarde (MON), Tarentaise (TAR), Normande (NOR), Simmental (SIM), and Vosgienne (VOS). 